\title{
Prevalence of excessive daytime sleepiness in Brazilian community-dwelling older adults with very low levels of schooling, and its association with sociodemographic characteristics and lifestyle: the Bambuí Health and Ageing Study (BHAS)
}

Prevalência de sonolência diurna excessiva em uma comunidade brasileira de idosos com baixa escolaridade e sua associação com características sociodemográficos e estilos de vida: Projeto Saúde e Envelhecimento Bambuí

Cláudia Hara , , Fábio Lopes Rocha', Érico de Castro e Costaª, Cíntia Fuzikawa², Elizabeth Uchoa², Maria Fernanda Lima-Costa

\begin{abstract}
Objective: Population-based studies on excessive daytime sleepiness (EDS) in older adults living in less developed countries are scarce. The purpose of this paper was to estimate the prevalence of EDS and its association with sociodemographic characteristics and lifestyle factors in Brazilian community-dwelling older adults. Methods: The study was carried out in Bambuí, a city in the state of Minas Gerais, Brazil. EDS was defined as the presence of sleepiness in the last month occurring three or more times per week, with any interference in usual activities. The exploratory variables were: gender, age, skin color, marital status, schooling level, current employment status, religion, recent migration, smoking, binge drinking and physical activities during leisure time. Results: Of 1,742 residents aged $\geq 60$ years, 1,514 (86.9\%) participated. The prevalence of EDS was 13\%. After adjustment for confounders, female gender and low schooling level remained positively and independently associated with EDS. Conclusions: The prevalence of EDS in the study population was within the range observed in studies carried out in developed

countries. The most impressive finding was the association of EDS with schooling, indicating that even in a population with low levels of schooling, this was an important factor to explain the distribution of EDS.
\end{abstract}

\section{Keywords}

Sleep disorders, elderly, survey.

\section{RESUMO}

Objetivo: Estudos populacionais sobre sonolência diurna excessiva (SDE) em idosos conduzidos em países em desenvolvimento são escassos. A proposta do presente trabalho é estimar a prevalência de SDE e sua associação com características sociodemográficas e

1 Medical Residency of Psychiatry - Psychopharmacology Course, Institute of Social Security of the Civil Servants of Minas Gerais, Belo Horizonte, Brazil

2 Public Health and Ageing Research Group (PHARG), Federal University of Minas Gerais Medical School and Oswaldo Cruz Foundation, René Rachou Research Institute.

3 Course of Medicine of the Health and Human Ecology School, Vespasiano, Brazil

Endereço para correspondência: Cláudia Hara

Medical Residency of Psychiatry - Course of Psychopharmacology, Institute of Social Security of the Civil Servants of Minas Gerais, Belo Horizonte, Brazil

E.mail: haracla@uol.com.br 


\section{Palavras-chave}

Distúrbios do sono, idoso, inquérito populacional. estilo de vida em idosos residentes em uma cidade brasileira. Métodos: Este estudo foi conduzido na cidade de Bambuí, localizada no Estado de Minas Gerais. SDE foi definida como presença de sonolência no último mês ocorrendo pelo menos três vezes por semana, com prejuízo das atividades. As variáveis exploratórias foram sexo, idade, cor da pele, estado civil, escolaridade, ocupação, religião, migração recente, tabagismo, uso excessivo de álcool e prática de atividade física. Resultados: Entre os 1.742 residentes com 60 anos ou mais, 1.514 (86,9\%) participaram. A prevalência de SDE foi 13\%. Após ajustamento por fatores de confusão, sexo feminino e menor escolaridade permaneceram positivamente associadas à SDE. Conclusões: A prevalência de SDE na população do estudo encontra-se dentro da faixa observada em estudos conduzidos em países desenvolvidos. Um achado relevante foi a associação de SDE com escolaridade, indicando que mesmo em uma população de menor nível de escolaridade, este é um fator importante na distribuição de SDE.

\section{INTRODUCTION}

Excessive daytime sleepiness (EDS) in older adults is considered a major clinical concern and an important public health problem ${ }^{1,2}$. In spite of EDS relevance, population- based studies of older individuals have so far been restricted to large cities of developed countries. The prevalence rates of EDS in these studies show a wide range from $1.1 \%$ to $28.6 \% \%^{3-18}$. Possibly, the main reason for this variation is the lack of a consistent definition of EDS. In addition, definitions used in these epidemiological studies did not meet the International Classification of Sleep Disorders definition of daily frequency of sleepiness that has a significant impact on usual activities ${ }^{19}$.

Factors associated with EDS in population-based studies might also be affected by the particular definition used. Reports of sociodemographic characteristics associated with EDS in population-based studies of older individuals have been inconsistent ${ }^{3-17}$. In addition, as far as we know there are no studies about lifestyle factors associated with EDS in older people. The present work addressed the study of EDS in older adults with very low levels of schooling, living in a small town of a developing country. The objectives of the study were: to determine the prevalence of EDS using operational criteria and to determine the sociodemographic characteristics and lifestyle factors associated with EDS.

\section{METHODS}

\section{The Bambuí Health and Ageing Study (BHAS)}

The BHAS is a population-based prospective cohort of older adults carried out in Bambuí, a city of 15,000 inhabitants in the state of Minas Gerais, Southeast Brazil. The data presented in this paper were collected at the baseline of the above-mentioned study. Further details can be found elsewhere ${ }^{20}$
All ethical requirements including informed consent and confidentiality were ensured. The project was approved by the Ethical Committee of the Fundação Oswaldo Cruz.

\section{Study population}

A complete census of the city was carried out by the BHAS research team between November and December of 1996 in order to identify the participants. All residents aged 60 years and over were selected for interview. Of 1,742 residents in this age group, 92.2\% were interviewed. Those interviewed and those examined were similar to the total population aged 60 years and over with respect to all of the sociodemographic characteristics considered: age, gender, number of residents in the household, marital status and education ${ }^{20}$

\section{Excessive daytime sleepiness}

The information about excessive daytime sleepiness was collected using a structured and codified sleep questionnaire adapted from a previously validated Brazilian mode $^{21-23}$ (Appendix A). Excessive daytime sleepiness was defined as the presence of sleepiness in the last month occurring three or more times per week, with any distress of usual activities. This distress was determined subjectively by the interviewee, according to his or her personal parameters of normal functioning 22,23 (Appendix A).

\section{Exploratory variables}

The information on sociodemographic characteristics and lifestyle factors was obtained through the baseline BHAS interview. The sociodemographic variables considered in this study were: gender, age, black skin color, marital status, number of complete years of schooling, current employment status, religion, and recent migration (migration to Bambuí city in the last 5 years).

The lifestyle factors were: current smoker (those who have smoked during their lifetimes and still smoke), binge 
drinking ( $\geq 5$ drinks on a single occasion in the last 30 days) and physical activity during leisure time for 20/30 minutes three times a week or more in previous 90 days.

The participants were also characterized in relation to some aspects related to sleep: onset of EDS complaint, presence of insomnia and use of sleeping pills. Insomnia was defined as the presence of any complaint (difficulty falling asleep, disrupted sleep and early morning awakening) at least three times a week with the presence of any distress during the last 30 days $^{24}$. The use of sleeping pills was defined as any number of sleeping pills taken in the last month. Information about insomnia and use of sleeping pills was collected using the sleep questionnaire previously described ${ }^{21,23}$.

The interviews were carried out by individuals selected by the researcher team among community members with at least 11 years of schooling. When a respondent was unable to participate because of a cognitive deficit or for some other health reason, a proxy was used (such as a family member or informal caregiver). Proxies were not asked questions that involved personal judgment or subjective aspects like the excessive daytime sleepiness complaint. The interviews were extensively trained by a psychiatrist with large previous experience in different countries and cultures (E Uchoa) ${ }^{24}$.

\section{Data analysis}

The univariate associations of sociodemographic characteristics and lifestyle factors with EDS were estimated, based on the $x^{2}$ test or $x^{2}$ test for linear trend $d^{25}$. Variables whose association was significant at $p \leq 0.20$ in this analysis were included in the initial multivariate model. The multivariate analysis was based on prevalence ratios estimated by robust Poisson regression ${ }^{26}$. Gender and age were a priori considered as confounding variables in this study and were included in the initial and final multivariate models. Other variables included in the initial multivariate model were black skin color, marital status, years of schooling, current employment status, and migration in the last 5 years. In the final model, only those which persisted associated with EDS at $p<0.05$ were retained, besides age. The analysis was carried out using the Stata software package, version 9.127.

\section{RESULTS}

Of 1,742 residents in Bambuí city aged 60 years and over, 1,514 (86.9\%) participated in this study: 138 did not participate in the baseline study and 90 were excluded because the interview was responded by a proxy. The mean age of the participants (39.0\% males and 61.0\% females) was 69.9 years (SD=7.1). The formal education of the study population was very low: only $8 \%$ presented 8 years of schooling or over. Further characteristics of the study sample are shown in Table 1.
Table 1. Selected characteristics of the study sample.

\begin{tabular}{|c|c|c|}
\hline Description & $\mathrm{n}$ & $(\%)$ \\
\hline \multicolumn{3}{|l|}{ Gender } \\
\hline Male & 591 & $(39.0)$ \\
\hline Female & 923 & (61.0) \\
\hline \multicolumn{3}{|l|}{ Age (years) } \\
\hline 60-64 & 512 & (33.8) \\
\hline $65-69$ & 395 & (26.1) \\
\hline $70+$ & 607 & (40.1) \\
\hline \multicolumn{3}{|l|}{ Black skin color } \\
\hline No & 1424 & $(94.0)$ \\
\hline Yes & 90 & (6.0) \\
\hline \multicolumn{3}{|l|}{ Marital status } \\
\hline Married/live together & 750 & (49.6) \\
\hline Single & 147 & (9.7) \\
\hline Separated/divorced & 79 & (5.2) \\
\hline Widowed & 538 & (35.5) \\
\hline \multicolumn{3}{|l|}{ Number years of schooling } \\
\hline $8+$ & 121 & (8.0) \\
\hline $4-7$ & 414 & $(27,5)$ \\
\hline $1-3$ & 504 & (33.4) \\
\hline None & 469 & (31.1) \\
\hline \multicolumn{3}{|l|}{ Current employment status } \\
\hline Working & 181 & (12.0) \\
\hline Not working & 1331 & (88.0) \\
\hline \multicolumn{3}{|l|}{ Religion } \\
\hline Catholic & 1429 & (94.4) \\
\hline Not catholic & 85 & (5.6) \\
\hline \multicolumn{3}{|l|}{ Migration in the last 5 years } \\
\hline No & 1368 & (93.6) \\
\hline Yes & 93 & (6.4) \\
\hline \multicolumn{3}{|l|}{ Current smoker } \\
\hline No & 1237 & (81.7) \\
\hline Yes & 277 & (18.3) \\
\hline \multicolumn{3}{|l|}{ Binge drinking } \\
\hline No & 1317 & $(87.0)$ \\
\hline Yes & 197 & (13.0) \\
\hline \multicolumn{3}{|c|}{ Physical activity during leisure time in previous 90 days ${ }^{b}$} \\
\hline No & 1313 & (86.7) \\
\hline Yes & 201 & (13.3) \\
\hline
\end{tabular}

The prevalence of EDS in the study population was 13\%. The prevalence of EDS was significantly higher among women (15.7\%) than among men (8.8\%); $(p<0.001)$. As a rule, EDS was higher among women than men across all age groups (Figure 1).

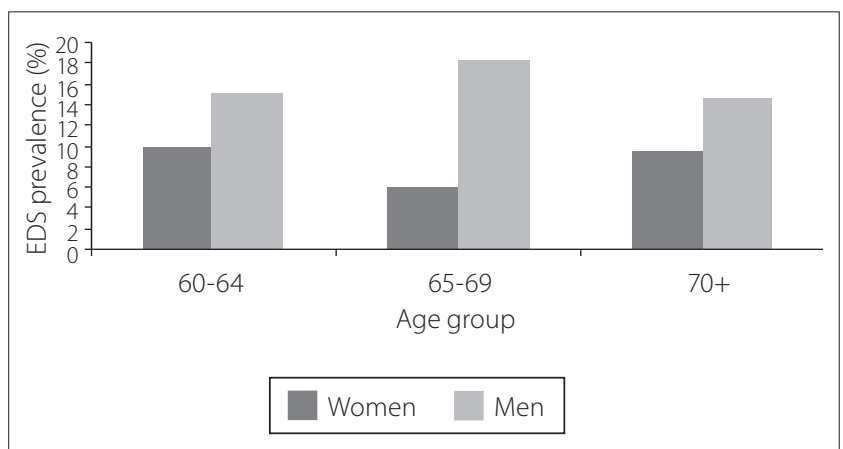

Figure 1. Age-sex prevalence of excessive daytime sleepiness in Bambuí City, Brazil. 
Some aspects related to sleep among participants with EDS are shown in Table 2. There was a predominance of chronic insomnia. Almost $60 \%$ had been suffering from insomnia for more than one year. Around 50\%, $62.4 \%$, and $35.5 \%$ suffered from initial, middle and terminal insomnia, respectively. Approximately $70 \%$ suffered from any complaint of insomnia. The use of sleeping pills in the last month was reported by $32.5 \%$ of the participants with EDS.

Table 2. Aspects related to sleep among older adults with excessive daytime sleepiness in the baseline of the Bambuí cohort study.

\begin{tabular}{lcc}
\hline Clinical description & \multicolumn{2}{c}{ Prevalence } \\
\cline { 2 - 3 } & $\mathbf{n}$ & $(\%)$ \\
\hline Onset of EDS complaint & 16 & $(8.1)$ \\
Less than one month & 28 & $(14.2)$ \\
Between one and six months & 37 & $(18.8)$ \\
Between six months and one year & 116 & $(58.9)$ \\
$\quad$ More than one year & & \\
Sleep during the day & 82 & $(41.6)$ \\
$\quad$ No sleep & 37 & $(18.8)$ \\
Until 30 minutes & 29 & $(14.7)$ \\
Between 30 minutes and one hour & 41 & $(20.8)$ \\
Between one hour and two hours & 8 & $(4.1)$ \\
More than two hours & & \\
Initial insomnia in the last 30 days & 106 & $(53.8)$ \\
$\quad$ No & 91 & $(46.2)$ \\
Yes & & \\
Middle insomnia in the last 30 days & 74 & $(37.6)$ \\
No & 123 & $(62.4)$ \\
Yes & & \\
Terminal insomnia in the last 30 days & 127 & $(64.5)$ \\
No & 70 & $(35.5)$ \\
Yes & & \\
Any complaint of insomnia in the last 30 days & 51 & $(25.9)$ \\
No & 146 & $(74.1)$ \\
Yes & & \\
Sleeping pills in the last 30 days & 133 & $(67,1)$ \\
No & 64 & $(32,5)$ \\
Yes & &
\end{tabular}

Table 3 shows the results of the univariate analysis of sociodemographic characteristics associated with EDS. In this analysis, EDS was significantly $(p<0.05)$ associated with female sex and years of schooling. Black skin color, marital status, current employment status, and migration status was associated with EDS at $p<0.20$ level.

Current smoker and physical activity during leisure time in previous 90 days were not associated with EDS in the univariate analysis. Binge drinking was found to be associated with EDS at $p<0.20$ level (Table 4).

The final results of the multivariate analysis of factors associated with EDS are shown in Table 5. Female gender and low years of schooling remained positively and independently associated with EDS.
Table 3. Results of the univariate analysis of sociodemographic characteristics associated with daytime sleepiness in the baseline of the Bambuí cohort study of older adults.

\begin{tabular}{|c|c|c|c|}
\hline \multirow[t]{2}{*}{ Sociodemographic characteristics } & \multicolumn{2}{|c|}{ Excessive daytime sleepiness } & \multirow[t]{2}{*}{ p value } \\
\hline & Yesn $(\%)$ & Non $(\%)$ & \\
\hline \multicolumn{4}{|l|}{ Gender } \\
\hline Male & $52(26.4)$ & $539(40.1)$ & \\
\hline Female & $145(73.6)$ & $778(59.1)$ & $<0.001$ \\
\hline \multicolumn{4}{|l|}{ Age (years) } \\
\hline 60-64 & $66(33.5)$ & $446(33.9)$ & \\
\hline $65-69$ & $54(27.4)$ & $341(25.9)$ & \\
\hline $70+$ & $77(39.1)$ & $530(40.2)$ & $0.903^{\prime}$ \\
\hline \multicolumn{4}{|l|}{ Black skin color } \\
\hline No & $180(91.4)$ & $1244(94.5)$ & \\
\hline Yes & $17(8.6)$ & $73(5.5)$ & 0.087 \\
\hline \multicolumn{4}{|l|}{ Marital status } \\
\hline Married/live together & $92(46.7)$ & $658(50.0)$ & \\
\hline Single & $14(7.1)$ & $133(10.1)$ & \\
\hline Separated/divorced & $16(8.1)$ & $63(4.8)$ & \\
\hline Widowed & $75(38.1)$ & $463(35.2)$ & 0.110 \\
\hline \multicolumn{4}{|l|}{ Number years of schooling } \\
\hline $8+$ & $6(3.0)$ & $115(8.8)$ & \\
\hline $4-7$ & $53(26.9)$ & $361(27.5)$ & \\
\hline $1-3$ & $65(33.0)$ & $439(33.5)$ & \\
\hline None & $73(37.1)$ & $396(30.2)$ & $0.008^{\prime}$ \\
\hline \multicolumn{4}{|l|}{ Current employment status } \\
\hline Working & $17(8.6)$ & $164(12.5)$ & \\
\hline Not working or retired & $180(91.4)$ & $1151(87.5)$ & 0.121 \\
\hline \multicolumn{4}{|l|}{ Religion } \\
\hline Catholic & $188(95.4)$ & 1241 (94.2) & \\
\hline Not catholic & $9(4.6)$ & $76(5.8)$ & 0.494 \\
\hline \multicolumn{4}{|l|}{ Migration in the last 5 years } \\
\hline No & $175(91.1)$ & $1193(94.0)$ & \\
\hline Yes & $17(8.8)$ & $76(6.0)$ & 0.130 \\
\hline
\end{tabular}

${ }^{a}$ in Brazilian minimum wages; $p$ value: $x^{2}$ test; $p^{\prime}$ value : $x^{2}$ for linear tend.

Table 4. Results of the univariate analysis of lifestyle factors and excessive daytime sleepiness among older adults residing in Bambuí city, Brazil.

\begin{tabular}{|c|c|c|c|}
\hline \multirow[t]{2}{*}{ Lifestyle factors } & \multicolumn{2}{|c|}{ Excessive daytime sleepiness } & \multirow[t]{2}{*}{ p value } \\
\hline & Yesn $(\%)$ & Non (\%) & \\
\hline \multicolumn{4}{|l|}{ Current smoker } \\
\hline No & $157(79.9)$ & $1080(82.0)$ & \\
\hline Yes & $40(20.3)$ & $237(18.0)$ & 0.434 \\
\hline \multicolumn{4}{|l|}{ Binge drinking } \\
\hline No & $178(99.4)$ & 1139 (86.5) & \\
\hline Yes & $19(9.6)$ & $178(13.5)$ & 0.132 \\
\hline \multicolumn{4}{|c|}{ Physical activity during leisure time in previous 90 days ${ }^{\mathrm{a}}$} \\
\hline No & $174(88.3)$ & $1139(86.5)$ & \\
\hline Yes & $23(11.7)$ & $178(13.5)$ & 0.478 \\
\hline
\end{tabular}

Table 5. Final model of the multivariate analysis of $\mathrm{s}$ sociodemographic and lifestyle factors associated with excessive daytime sleepiness in the baseline of the Bambui cohort study of older adults.

\begin{tabular}{|c|c|c|c|}
\hline \multirow[t]{2}{*}{ Variable } & \multicolumn{2}{|c|}{ Excessive daytime sleepiness } & \multirow[t]{2}{*}{$\operatorname{PR}(95 \% \mathrm{Cl})^{*}$} \\
\hline & Yesn (\%) & Non (\%) & \\
\hline \multicolumn{4}{|l|}{ Gender } \\
\hline Male & $52(8.80)$ & $539(91.2)$ & 1.00 \\
\hline Female & $145(15.7)$ & $778(84.3)$ & $1.75(1.27-2.40)$ \\
\hline \multicolumn{4}{|c|}{ Number years of schooling } \\
\hline $8+$ & $6(4.9)$ & $115(95.1)$ & 1.00 \\
\hline $4-7$ & $53(12.8)$ & $361(87.2)$ & $2.54(1.09-5.90)$ \\
\hline $1-3$ & $65(12.9)$ & $439(87.1)$ & $2.53(1.10-5.84)$ \\
\hline None & $73(15.6)$ & $396(84.4)$ & $3.02(1.31-6.94)$ \\
\hline
\end{tabular}

* Prevalence ratio and $95 \%$ robust confidence interval adjusted for the variables listed in the table plus age, using Poisson regression. 


\section{DISCUSSION}

EDS was reported by $13 \%$ of older adults residing in the study area. This prevalence rate was inside the range of five population based studies on EDS of older adults $3,6,8,15,16$ and ten population based studies of adults, including older subjects $5,7,9-14,17,18$. As mentioned before, the broad range of prevalence of EDS in these studies (1.1\% to $28.6 \%)$ is related at least in part to the methodological differences, mainly due to the definition of sleepiness. The definition used in the present study meets the International Classification of Sleep Disorders criteria considering the presence, frequency and distress of usual activities. As far as we know, there is no study with older people that have estimated the prevalence of EDS taking into account its consequences for usual activities $^{28}$. Considering the populational studies in older adults, the definition used in the study carried out in Japan was more restrictive than the one used in the present study. In $60+$ years old people, Kaneita et al. ${ }^{9}$ found a prevalence rate of $1.1 \%$ of the excessive daytime sleepiness measured according to a question "Do you fall asleep when you must not sleep (for example when you are driving a car)?". Hays et al. ${ }^{8}$, which reported the highest prevalence (25.2\%), identified EDS using the following question: "How often do you get so sleepy during the day or evening that you have to take a nap? (most of the time vs. sometimes, rarely, or never). This question could take into account either EDS and natural naps.

Other methodological differences can also explain some reported dissimilarities in EDS prevalence, such as age of the study population and face to face versus telephone interview. Barbar et al. ${ }^{4}$ studied old Japanese American men (mean age 78 years) residing in Hawaii and found a prevalence of EDS equal to $8.9 \%$. On the other hand, Baldwin et al. ${ }^{3}$ found a prevalence of $24.8 \%$, using the Epworth Sleepiness Scale and included in a younger population (mean age 63 years). Most studies were performed using face to face interview ${ }^{3-5,7-11,15,16}$, but some studies were performed using telephone interview using a computer-assisted program ${ }^{13}$. In the present study, the mean age of the participants was 69 years and all information about EDS was obtained through face to face interview.

The definition used in this study may appear to suggest a point prevalence of the symptom in the last month rather than a persistent problem. However, almost $80 \%$ of the individuals with EDS had been suffering from it for more than six months, that is to say chronic EDS.

More than half of the individuals with EDS reported sleep during the day and $45 \%$ of these described more than 30 minutes of sleep during the day and approximately $20 \%$ reported more than one hour. The naps would reduce the daily sleep requirement and also daytime sleepiness. Some older people take afternoon naps to compensate for the "lost" sleep time at night. However, the naps would to result in a vicious circle. Refraining from naps could help the older people to achieve better sleep at night, to reduce the daytime sleepiness, and thus acquire a better and regular sleeping pattern.

The majority of individuals with EDS reported at least one complaint of insomnia, initial, middle or terminal insomnia. Disrupted sleep has been reported to be a major cause of EDS. Hays et al. ${ }^{8}$ that found one-third of respondents with EDS in North Carolina reported high levels of "nighttime sleep complaints".

Almost the third part of the individuals with EDS took sleeping pills in the last month. The EDS could be explained by the residual effects of sleeping pills, particularly among old people. On the other hand, sleeping pills can alleviate insomnia, a condition frequently associated with EDS.

An association between EDS in older adults and female gender has been found in some studies ${ }^{8,16}$. Other studies have reported higher prevalence among males, $3,0,14$. Theoretically, one could expect higher prevalence of EDS among women, as a consequence of some health problems, which are more common among them and are also related to EDS, like depression, insomnia, and restless legs syndrome $23,29,30$. In our study, female sex was independently associated with EDS.

Schooling was the strongest variable associated with EDS, being more prevalent among individuals with lower years of schooling. This association was not found in a previous study of older adults carried out in North Carolina, US $^{8}$. In our study, the association between EDS and formal education is plausible due to the higher prevalence of health problems, sleep disorders and psychiatric disorders among older adults with low schooling level in the study area $5,7,8,13,23,29$.

No association between EDS and age was found in the Bambuí study. The association between age and EDS is controversial. Such association was found in one study carried out in California (US) ${ }^{15}$ but this was not found in four others studies carried out in Arizona (US), North Carolina (US) and in Canada ${ }^{3,6,8,16}$.

We did not found any association between EDS and marital status, black skin color, current employment status, religion, and migration in the last 5 years. In a previous study in North Carolina, an association between EDS and not being married was not found ${ }^{8}$.

In Bambuí, we did not also find any association between EDS and current smoker, binge drinking, and physical activity during leisure time in previous 90 days also. In the National Sleep Foundation's Sleep in America Poll, EDS predicted low exercise frequency ${ }^{6}$.

EDS can be a result of several other conditions including insufficient sleep syndrome, sleep disordered breathing, 
circadian rhythm disorders, shift work, idiopathic hyper somnolence and narcolepsy. Further studies are needed to evaluate such relationships in older adults. The high prevalence of EDS among older adults in the study area indicates that it is an important health problem in this population with very low school level. Feminine gender and low years of schooling were the sociodemographic characteristics independently associated with EDS. The burden of EDS in this small town seems to be as high as that observed in developed countries. Even in this economically poor town, social differences (represented by a lower education) were an important factor in explaining the distribution of EDS. As far as we know, this is the first community-dwelling older people study on EDS carried out in a small town (Bambuí) in a developing country (Brazil) and the first communitydwelling older people study that has estimated the prevalence of EDS taking into account the impact of usual activities, according to the International Classification of Sleep
Disorders definition. It is necessary to verify if these results are replicated in other towns of Brazil as well as in other developing countries.

\section{CONCLUSION}

The prevalence of EDS in the study population was within the range observed in studies carried out in developed countries. The most impressive finding was the association of EDS with schooling, indicating that even in a population with low levels of schooling, this was an important factor to explain the distribution of EDS.

Conflict of interests: Financing: This study was supported by the Brazilian Agency of studies and projects (FINEP). M.F. Lima-Costa and E Uchoa are fellows of the Brazil's National Council for Scientific and Technological Development (CNPq).

\section{APPENDIX A}

\section{Sleep Questionnaire Excessive Daytime Sleepiness Section}

The following questions relate to your sleep habits only during the last month.

Now, we would like to know if you had some kind of bother or problem related to your sleep in the last month. For each of the questions, please choose the best answer from the ones that I will read.

1 During the last month, how often did you feel daytime sleepiness?

(1) Not during the last month

(2) Less than once a week

(3) Once or twice a week

(4) Three or more times a week

2 During the last month, has daytime sleepiness caused any impairment (problems) in your usual activities?

(1) No problem at all

(2) Only a very slight problem

(3) Somewhat of a problem

(4) A very big problem

(8) No daytime sleepiness during the last month

3 How long have you had daytime sleepiness?

(1) Only in the last month

(2) From one to six months

(3) From six months to one year

(4) More than one year. Specify:_______ years

(8) No daytime sleepiness during the past month or no problem at all

4 During the last month, how often have you taken medicine to improve daytime sleepiness?

(1) Not during the last month

(2) Less than once a week

(3) Once or twice a week

(4) Three or more times a week

5 During your entire life, considering all periods, how often have you taken medicine to improve daytime sleepiness?

(1) Never

(2) Once a month or less than that

(3) From one to six months

(4) From six months to one year

(5) More than one year. Specify: years 
6 More recently, who indicated the medicine that you have taken to improve daytime sleepiness?

(1) The interviewer himself

(2) A family member

(3) A neighbor or a friend

(4) Pharmacist

(5) Doctor

(6) Other:

(8) Never taken

7 Is there anything that you are used to doing or taking to improve daytime sleepiness? (If the interviewed person answers no, give examples: bath, coffee, tea, soft drink, etc) (Assign yes=1 or no=2)

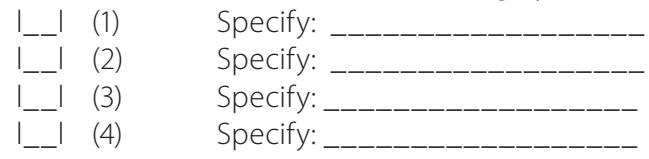

8 Now, I am going to narrate other problems related to sleep. In the last month, had you some kind of these problems? Please answer yes or no for each of the questions.

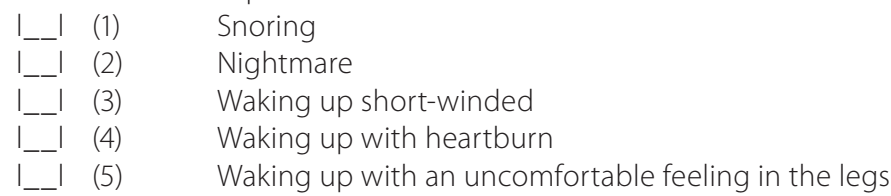

\section{REFERENCES}

1. Bliwise DL. Sleep in normal aging and dementia. Sleep. 1993;1640-81.

2. Whitney CW, et al. Correlates of daytime sleepiness in 4578 elderly persons: the Cardiovascular Health Study. Sleep. 1998;21:27-36.

3. Baldwin CM, et al., The association of sleep-disordered breathing and sleep symptoms with quality of life in the Sleep Heart Health Study. Sleep. 2001;24:96-105.

4. Barbar SI, et al. Sleep disturbances and their correlates in elderly Japanese American men residing in Hawaii. J Gerontol A Biol Sci Med Sci, 2000;55:M406-11.

5. Bixler E0, et al. Prevalence of sleep disorders in the Los Angeles metropolitan area. Am J Psychiatry. 1979;136:1257-62.

6. Chasens ER. et al., Daytime sleepiness, exercise, and physical function in older adults. J Sleep Res. 2007;16:60-5.

7. Ford DE, Kamerow DB. Epidemiologic study of sleep disturbances and psychiatric disorders. An opportunity for prevention? JAMA, 1989;262: 1479-84.

8. Hays JC, Blazer DG, Foley DJ. Risk of napping: excessive daytime sleepiness and mortality in an older community population. J Am Geriatr Soc. 1996;44:693-8.

9. Kaneita Y, et al. Excessive daytime sleepiness among the Japanese general population. J Epidemiol. 2005;15:1-8.

10. Klink M, Quan SF. Prevalence of reported sleep disturbances in a general adult population and their relationship to obstructive airways diseases. Chest. 1987;91:540-6.

11. Liu X, et al. Sleep loss and daytime sleepiness in the general adult population of Japan. Psychiatry Res. 2000;93:1-11.

12. Ng TP, Tan WC. Prevalence and determinants of excessive daytime sleepiness in an Asian multi-ethnic population. Sleep Med. 2005;6:523-9.

13. Ohayon MM, et al. How sleep and mental disorders are related to complaints of daytime sleepiness. Arch Intern Med. 1997:157:2645-52.

14. Pallesen $\mathrm{S}$, et al. Prevalence and risk factors of subjective sleepiness in the general adult population. Sleep. 2007;30:619-24.

15. Roberts RE, et al., Sleep complaints and depression in an aging cohort: A prospective perspective. Am J Psychiatry. 2000;157:81-8.
16. Rockwood K, et al. Sleep disturbances and mortality: results from the Canadian Study of Health and Aging. J Am Geriatr Soc. 2001;49:639-41.

17. Souza JC, Magna LA, Reimao R. Excessive daytime sleepiness in Campo Grande general population, Brazil. Arq Neuropsiquiatr. 2002;60:558-62.

18. Vela-Bueno A, De Iceta M, Fernandez C. Prevalence of sleep disorders in Madrid, Spain. Gac Sanit. 1999;13:441-8.

19. International Classification of Sleep Disorders: Diagnostic and Coding Manual, revised. 1997, Rochester, Minn: American Sleep Disorders Association.

20. Costa MF, et al. The Bambui health and ageing study (BHAS): methodological approach and preliminary results of a population-based cohort study of the elderly in Brazil. Rev Saude Publica. 2000;34:126-35.

21. Giglio S. Estudo da ocorrência das queixas de insônia, sonolência excessiva dourna e das relativas às parassonias na população adulta da cidade de São Paulo. Escola Paulista de Medicina. 1988.

22. Hara CLRF, Lima-Costa MF. Prevalence of excessive daytime sleepiness and associated factors in a Brazilian community: the Bambui study. Sleep Medicine. 2004;5:31-6.

23. Rocha $\mathrm{FL}$, et al., Prevalence of sleep complaints and associated factors in community-dwelling older people in Brazil: the Bambui Health and Ageing Study (BHAS). Sleep Med. 2002;3:231-8.

24. Lima-Costa MF, et al. The Bambui health and ageing study (BHAS): methodological approach and preliminary results of a population-based cohort study of the elderly in Brazil. Rev Saude Publica. 2000;34:126-35.

25. Cornfield J. A statistical problem arising from retrospective studies, in case-control studies. SchlessIman J. editor. Oxford University Press, Inc. 1982.

26. Zou G. A modified poisson regression approach to prospective studies with binary data. Am J Epidemiol. 2004;159:702-6.

27. StataCorp: Stata Statistical Software, R.C.S., TX: StataCorp LP; 2005.

28. Young TB. Epidemiology of daytime sleepiness: definitions, symptomatology, and prevalence. J Clin Psychiatry. 2004;65 Suppl 16:12-6.

29. Vorcaro CM, et al. Unexpected high prevalence of 1-month depression in a small Brazilian community: the Bambui Study. Acta Psychiatr Scand. 2001;104:257-63.

30. Krishnan V, Collop NA. Gender differences in sleep disorders. Curr Opin Pulm Med. 2006;12:383-9. 